\title{
Artigo
}

\section{O JARDIM DAS FLORES DE PLÁSTICO: CAMINHOS POÉTICOS DE UM TEATRO NEGRO E PERIFÉRICO*}

\author{
O JARDIM DAS FLORES DE PLÁSTICO: \\ POETICS WAYS OF A BLACK AND PERIPHERAL THEATER
}

O JARDIM DAS FLORES DE PLÁSTICO:

FORMAS POÉTICAS DE UN TEATRO NEGRO Y PERIFÉRICO

\section{Altemar Di Monteiro}

\author{
Altemar Di Monteiro \\ Ator e diretor do Nóis de Teatro, em Fortaleza. \\ Atualmente é doutorando em artes da cena \\ pela Escola de Belas-Artes da Universidade \\ Federal de Minas Gerais.
}

* Texto integrante da dissertação de mestrado Caminhares periféricos: Nóis de Teatro e a potência do caminhar no teatro de rua contemporâneo (MONTEIRO, 2017) pela Universidade Federal do Ceará, com bolsa Funcap e orientação de Héctor Andres Briones Vásquez. 


\section{Resumo}

Levantando discussões a partir de O jardim das flores de plástico-Ato 3: por baixo do saco preto, espetáculo-cortejo vencedor do 3ํㅜㄹêmio Nacional de Expressões Culturais Afro-Brasileiras, montado em 2015 com os atores do Nóis de Teatro, na periferia de Fortaleza, CE, este artigo busca refletir sobre os cruzamentos poéticos e políticos do teatro produzido pelos artistas negros do grupo na tessitura de rearranjos sobre o discurso hegemônico de cidade.

Palavras-chave: Teatro negro, Periferia, Caminhar.

\section{Abstract}

Raising discussions from 0 jardim das flores de plástico - Ato 3: por baixo do saco preto winning show at the 3rd National Afro-Brazilian Cultural Expression Prize (Cadon/Petrobras), done in 2015 with the actors of Nóis de Teatro, on the peripheral of Fortaleza -CE, the present article seeks to reflect on the poetic and political intersections of the theatre produced by black artists from the group in the rearrangement of the hegemonic discourse about city.

Keywords: Black theatre, Periphery, Walk.

\section{Resumen}

Desde O jardim das flores de plástico - Ato 3: por baixo do saco preto, pieza ganadora del $3^{\circ}$ Premio Nacional de Expresiones Culturales Afrobrasileñas, montada en el 2015 en la periferia de Fortaleza con los actores del Nóis de Teatro, este artículo propone reflexionar sobre los cruces poéticos y políticos del teatro producido por el grupo de artistas negros en el reordenamiento del discurso hegemónico en la ciudad.

Palabras clave: Teatro negro, Periferia, Caminar.

Experimentar o experimental A fala da favela

O nódulo decisivo nunca deixou de ser o ânimo de plasmar uma linguagem convite para uma viagem.

(Waly Salomão)

Este artigo busca refletir sobre os cruzamentos poéticos e políticos do teatro produzido pelos artistas negros do Nóis de Teatro na tessitura de rearranjos sobre o discurso hegemônico de cidade. Existente há 15 anos no bairro 
Granja Portugal - "Território de Paz" do Grande Bom Jardim¹ - o Nóis de Teatro, coletivo do qual participo como encenador teatral, que possui uma produção estética que se forja a partir da relação com o bairro onde moramos, evidenciando uma poética que, na sua singularidade política, aponta para processos de reinvenção da experiência de cidade.

Espetáculo vencedor do terceiro Prêmio Nacional de Expressões Culturais Afro-Brasileiras (Cadon/Petrobras), montado em 2015 com os atores do Nóis de Teatro², O jardim das flores de plástico é uma série de intervenções performativas que surgiu no turbilhão de uma pesquisa que parte do anseio de construir uma arte que dialogue com a cidade. Realizado somente por atores negros, o espetáculo saúda a rua num cortejo cênico, dialogando com e na periferia, tendo como argumento paralelo o debate sobre o abafado genocídio da juventude negra da cidade. A partir da imagem do saco de lixo preto usado por legistas para cobrir cadáveres, começamos, neste trabalho, a nos perguntar sobre o que a sociedade vai julgando como lixo social e humano e o que ela vai relegando a um plano de obliteração. Perguntando-nos sobre quais imagens da periferia urbana vêm sendo reiteradas, o Nóis tenta revelar o que há de oculto e dissensual por baixo desse saco preto. Marcados pelo ritmo dolente do maracatu cearense, a intervenção tomava as ruas numa ação que se fazia caminhando. Convocando o espectador a caminhar pelo próprio bairro, a cena, a partir da arquitetura e topografia vivenciadas, buscava produzir litígios no discurso do medo e violência que habita a cidade ${ }^{3}$. A partir desse trabalho e diante das diversas normatizações das vidas e do urbano, pergunto sobre quais os alcances desse teatro, feito na periferia de Fortaleza, na construção de situações poéticas que inflamem dissensos descoloniais em nossa regimentalizada experiência de cidade. Caminhando pelo bairro - seja no processo de montagem do espetáculo ou no que evidenciávamos de experiência ao espectador - topávamos quase sempre com o não dito pelo projeto urbano

1. O Grande Bom Jardim é um amplo território composto por um complexo mapa de bairros da Secretaria Executiva Regional V de Fortaleza.

2. Atualmente o grupo é formado por Altemar Di Monteiro, Edna Freire, Henrique Gonzaga, Kelly Enne Saldanha, Jefferson Saldanha, Amanda Freire, Nayana Santos, Bruno Sodré e Doroteia Ferreira. Para a montagem de $O$ jardim das flores de plástico - Ato 3, convidamos ex-integrantes e parceiros para integrar o elenco: Jonas de Jesus, Angélica Freire, Gil de Souza e Gleilton Silva.

3. Para acessar o vídeo-resumo do espetáculo, confira: <http://bit.ly/2tSmzwQ>. 
oficial, o que nos levava a absorver, passo a passo, uma voz destoante que, aos murmúrios, tem clamado por escuta. Daí que lançando uma voz que parte de uma periferia urbana tecida por artistas negros reflito sobre o que o caminhar, como prática de espaço em fluxo, oferece de potência crítica e criativa para o trabalho do artista que se lança a esse vertiginoso desafio.

Reconhecendo a possibilidade dissensual e descolonial de uma formação discursiva que se rabisca a partir do sensível e incessantemente efêmero do mundo, começamos a reconhecer a insurgência de um teatro que, reagindo à totalização das paralisias, orienta-se a partir do fluxo enquanto desejo e vertigem, gerando rotas de fuga às manobras estratégicas de um urbanismo viciado na higienização e segregação da urbe. Esse intento foi o que contribuiu para pensarmos na realização de um teatro em cortejo, debatendo o entorno de nossa sede, o entorno de nós mesmos: artistas jovens, negros, periféricos. Dessa maneira, todas as vivências com nosso bairro - aliadas ao desejo em produzir e difundir um teatro de matriz negra - e o espetáculo são relevantes, principalmente diante dos alarmantes números do abafado genocídio cometido contra a juventude negra de nossas periferias ${ }^{4}$, estratégia biopolítica de uma cidade que se faz militarizada e esterilizante.

\section{A periferia tem sua cor}

América nos conduce a África; las naciones de Europa y Asia se reúnen en Australia; los márgenes de la nación desplazan el centro; los pueblos de la periferia regresan para reescribir la historia y la ficción de la metrópoli.

(Homi K. Bhabha)

Ainda é muito comum ouvir dizer que, no Ceará, não há população negra, que a escravidão praticamente não existiu devido à seca e que aqui só existem comunidades indígenas. Esse discurso faz que muitos ainda não

4. O relatório Índice de vulnerabilidade juvenil à violência e desigualdade racial 2014 , da Presidência da República, reconhece que os "homicídios mostram-se como a grande tragédia da população jovem negra hoje no Brasil" (BRASIL, 2015, p. 14). O relatório menciona ainda "as altas taxas de violência observadas no país contra adolescentes e jovens entre 12 e 29 anos de idade, em especial jovens negros, que, em 2013, foram 18,4\% mais encarcerados e $30,5 \%$ mais vítimas de homicídios dos que os jovens brancos, segundo

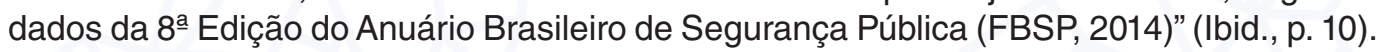


reconheçam a influência da cultura afro na construção de nossa identidade. Um fato importante que contribui para essa leitura equivocada foi a "abolição" da escravatura que, historicamente, teria acontecido primeiro no Ceará, na cidade de Redenção. Mas o que se esquece de pontuar é que, quando os escravos saíram da situação de cativos, a estratégia fundante da casa-grande foi afastá-los dos centros urbanos e das elites, deixando-os às margens, formando, assim, as favelas e periferias das cidades contemporâneas, que se tornaram a moradia desses novos "cidadãos" que acumulam a discriminação e o preconceito. A periferia tem sua cor.

Nesse contexto, vamos percebendo que, em pleno século XXI, grande parte dos moradores dos bairros periféricos de Fortaleza ainda vieram do interior do Estado, alimentando esses lugares com um estilo de vida que transita entre o tempo acelerado de uma juventude conectada com a informação global e a nostalgia rural de uma geração que tentou sobreviver vindo para as ditas "cidades grandes." O paradoxo habita inelutavelmente nesses lugares, revelando ao Nóis de Teatro tensões socioculturais que são agenciadoras de criação artística. São espaços que produzem imagens que não cessam de se reinventar, um dizer que não cessa de se contradizer, imagens puxadas ora pela totalização de uma visão de mundo absorta pela comunicação em massa, ora, fincada num sentimento de pertencimento e resistência territorial simbólica, afetiva e comunitária. Assim sendo, durante nossos processos criativos, o Nóis de Teatro tem-se perguntado sobre o que a periferia pode dizer sobre a cidade, para além da violência que já ouvimos reiteradas vezes a partir de uma visão centralizadora, militarizada, esterilizada, higienizadora e embranquecida.

O que hoje se percebe na construção das cidades contemporâneas, sobretudo em Fortaleza, vista como o segundo maior destino turístico do Nordeste, é um processo de esterilização dos espaços, ou ainda, privatização das afetividades, limitando cada vez mais as práticas de sociabilidades públicas e ocultando os tensionamentos socioculturais e políticos existentes nos discursos que constroem a urbe.

A forma mais recorrente e aceita hoje desse processo esterilizador faz parte do processo mais vasto de espetacularização das cidades e está diretamente relacionado com a pacificação dos espaços urbanos, em 
particular, dos espaços públicos. A pacificação do espaço público, através da fabricação de falsos consensos, busca esconder as tensões que são inerentes a esses espaços e, assim, procura esterilizar a própria esfera pública, o que, evidentemente, esteriliza qualquer experiência e, em particular, a experiência da alteridade nas cidades. (JACQUES, 2012, p. 14)

Por esse ângulo, parece que as periferias demostram, mesmo que inconscientemente, um dissenso à noção desse desenvolvimento acelerado da cidade-estéril espetacularizada. Nesses lugares, penso que é possível perceber espaços públicos ainda tomados pelo sentimento de comunidade partilhada, lugares de trânsito de afetividades em convívio. Nas ruas do bairro onde atuamos, por exemplo, ainda é possível ver as pessoas nas calçadas, nas ruas, lugares onde as crianças ainda brincam e são tomadas por esse espírito quase melancólico de espaço público e social, noção tão difícil de ser partilhada na cidade-estéril e falsamente pacificada, permeada de grandes condomínios, esquemas de segurança e vigilância eletrônica, uma imagem fabricada por um sistema muito mais preocupado com os rendimentos lucrativos de um negócio do que com a produção de espaços dialógicos, de relacionamentos e afetividades.

Contudo, buscando não idealizar a imagem dessa periferia, colocando-a de um lado e a cidade do outro, como se ela não fizesse parte dessa mesma cidade que se esteriliza e espetaculariza, será importante a reflexão que o crítico de arte brasileira, Moacir dos Anjos (2005, p. 15), levanta quando nos fala que global e local são "termos relacionais - assim como o são centro e periferia -, e não descrições de territórios físicos ou simbólicos bem definidos e isolados". Por essa lógica, é possível dizer que a construção dos sentidos sobre a cidade não acontece somente numa linha vetorial centro-periferia, mas também valida-se na contramão periferia-centro. Essa percepção é que revela outros olhares sobre a pólis esterilizada, gerando significados dissensuais sobre a cidade contemporânea, dando sinais, inclusive, de como essa esterilização pode e talvez venha chegar aos bairros da periferia.

É compreendendo a complexidade dessa teia, que parece ser de grande pertinência nesse chamado de escuta ao que a margem pode dizer sobre o centro de um rio em fluxo, e entendendo o trabalho artístico do Nóis de Teatro não como uma ação local, de interesse apenas para os moradores do bairro 
ou de sua população negra, mas ampliando-o como potência de discussão e reescrita da história e ficção da metrópole, o que vale dizer que pensar a periferia significa, inelutavelmente, também pensar a cidade.

Assim sendo, os artistas do grupo, ao caminhar pela periferia em seus processos criativos, são desafiados à compreensão dessas dinâmicas que compõem a voz que escutamos em nossas imersões poéticas, tentando desarrumar as linhas escritas da cidade onde habitamos. Interessados nas amnésias desse aparente espaço vazio, inquieta-nos olhar a periferia de modo crítico, buscando compreender os interstícios dos discursos inscritos nas arquiteturas, topografias e geografias da cidade. Em que medida, então, $O$ jardim das flores de plástico reconta e refaz a memória da cidade? Discernindo esses intensos cruzamentos que constituem a metrópole, de que forma a periferia nos provoca e convoca a pensar toda a cidade?

\section{Seja marginal, seja herói}

Inquietos com a questão lançada anteriormente, o Nóis de Teatro tem-se perguntado sobre quem são esses indivíduos que estão nas esquinas das periferias, chamados muitas vezes de "vagabundos", "marginais", quase sempre pobres e pretos, e, vez ou outra, integrantes dos números de violência e genocídio da juventude na periferia. Enquanto parte da sociedade observa-os com medo do que eles possam fazer, atentos a esse olhar "ocioso" que já mapeou todas as arquiteturas, percursos e trajetos do bairro, o Nóis de Teatro vem lançando-se à inquietude de compreender essa visão de mundo. As madrugadas estão habitadas por esses "vagabundos", lançados à espreita, donos do espaço, nas ruas como se estivessem em casa. Do que esses "marginais" precisam para essa propriedade tão manifesta sobre o espaço? É importante pensarmos em como sua relação com a comunidade foi afastada: talvez pela sua disposição em relação ao espaço e ao outro, ou mesmo pela própria construção dos discursos sobre sua atuação no território que, de forma tão misteriosa, nos leva ao medo e ao afastamento. Contudo, não há como negar o potencial dessa tensão na cidade, material que tem inquietado o trabalho poético do Nóis de Teatro. É buscando uma atenção especial a esses "marginais urbanos" que vamos percebendo o que de marginal e de 
burguês que carregamos enquanto artistas, inquietando-nos, constantemente, sobre nossa atuação nas ruas e o tônus de contrassenso e vagabundagem que nosso teatro provoca no espaço público.

Em nosso trabalho, são horas entregues à rua, às esquinas, jogando-nos em um ócio criativo e uma apropriação desmedida de um tempo em suspenso. Nesse processo, vai se tornando comum sermos chamados de "desocupados" ou questionados sobre onde está nosso trabalho, o que nos coloca cada vez mais no rastro de um contrafluxo, desmistificando, inclusive, o padrão militarizado de um policiamento 5 ávido por "vigiar e punir" o jovem periférico "desocupado" nas pontas das esquinas.

Nosso repertório busca rever, a partir de um olhar que se lança estando na periferia, as imagens fabricadas sobre esses sujeitos periféricos. Em $O$ jardim das flores de plástico, levantamos uma cena teatral que possui como protagonista - ou anti-herói - uma personagem que vaga e transita pelas vias, revestida de mistérios. A personagem "Homem de Branco", interpretada pelo ator Gilvan Sousa, caminhava pelas ruas, elevada por penas de pau, com o rosto coberto e tecidos esvoaçantes, inserindo na narrativa a alegoria desse olhar de medo que a sociedade normatizada coloca sobre os habitantes - sobretudo os negros - da periferia. A narrativa levanta um grande mistério quanto aos números da violência urbana que está assolando dada comunidade. $A$ partir daí, todas as personagens vão culpando esse homem, vendo-o como o perigo, o inimigo central ${ }^{6}$ que deve ser urgentemente derrotado, metáfora ligada ao embrutecimento de uma sociedade que não percebe que seus conflitos

5. É importante pontuar quanto o discurso do policiamento, sobretudo o militarizado, tem atuado de forma categórica nos espaços de sociabilidade das cidades, em especial nas periferias. Por aqui, a relação com a polícia parece seguir outra lógica, bem diferente das vivenciadas nos centros urbanos da capital, já que a população periférica, sobretudo a negra e pobre, vai sendo vista pela corporação como alvo constante de suas investidas estratégicas de "segurança pública". Nesse sentido, ao pensar numa cidade avivada em poética e arte, estamos certamente atuando na busca por fugir dessa cidade militarizada, onde o policiamento é quem coreografa a urbe, como nos aponta André Lepecki (2012, p. 52): "o policiamento enquanto coreografia do fluxo do cidadão é algo profundamente arraigado, entranhado e que forma e deforma o espaço do urbano e o imaginário social de circulação nesse espaço [...] A polícia, em outras palavras, coreografa. Ou seja, é ela que garante que, desde que todos se movam e circulem tal como lhes é dito (aberta ou veladamente, verbal ou espacialmente, por hábito ou por porrada)."

6. Inseridos nos estudos sobre as poéticas e dramaturgias de origem africana, foi muito importante para o grupo assistir ao longa-metragem de animação franco-belga Kiriku e a feiticeira (1998), de Michel Ocelot. 
sociais estão para além do maniqueísmo ocidentalizado de bem e mal, culpado e inocente. Somente quando os tecidos brancos que cobrem o Homem são retirados, é que se desvela uma imagem bem mais complexa que a lenda urbana criada poderia suspeitar: um homem negro, vítima de uma série de violências, assim como todos os outros que o julgavam desde o começo ${ }^{7}$.

Por essa linha, é inevitável não tecer paralelos com as vivências de Hélio Oiticica quando chega ao Morro da Mangueira, no Rio de Janeiro, nos anos 1970. "Seja marginal, seja herói", essa era uma das principais premissas de Oiticica ao pensar na descentralização da arte, incorporando o Morro da Mangueira em sua obra e influenciando toda a produção cultural de uma geração. No intrigante livro Cidade partida (1994), Zuenir Ventura faz um levantamento da conjuntura sociopolítica do Rio no final do século XX a partir da guerra declarada da sociedade contra os bandidos, dos embates entre "morro" e "asfalto". Ventura fala-nos da pertinência do trabalho de Oiticica na produção de dissensos sobre o universo das favelas:

Fascinado pela marginalidade, passista da Mangueira, companheiro de malandros e bandidos, frequentador de favelas, Oiticica "foi o maior inventor de arte brasileira", segundo o crítico Frederico de Morais. Radical, ele considerava a arte como revolta e essa revolta era, na opinião de Morais, "semelhante à do bandido que rouba e mata, em busca de felicidade, mas também à do revolucionário político". (VENTURA, 1994, p. 38-39)

Assim, nesse exercício de alteridade, Oiticica busca rever suas obras através da marginália (ou cultura marginal), o que inclui, nessa instância, o desvio do olhar preconceituoso e militarizado da sociedade sobre esses indivíduos. Dessa maneira, Oiticica buscava, em suas caminhadas, perambulando com inteligência, desmitificar a experiência no espaço público a partir de um olhar

7. Outro espetáculo de nosso repertório, Todo camburão tem um pouco de Navio Negreiro, narra a saga de uma personagem negra que de oprimida passa a ser opressora. Ao assassinar um jovem na periferia, a personagem, que também nasceu na comunidade, vai a tribunal e são os espectadores, como júri popular, que decidem o futuro de nosso herói, na maioria das vezes levantando argumentos e tensionando os discursos apresentados.

8. "Seja marginal, seja herói" é uma bandeira-poema feita por Hélio Oiticica em 1968 em homenagem a seu amigo Cara de Cavalo, um famoso traficante morto em 1964. A bandeira emblematizou nos anos 1970 toda uma produção cultural que passou a ser conhecida como "marginália", influenciando artistas de cinema (Rogério Sganzerla e Ozualdo Candeias), da poesia (Wally Salomão e Torquato Neto) e da música (Jards Macalé e Luiz Melodia). 
diferenciado, na tentativa de fuga das rotas hegemônicas que operam sobre o espaço observado e acionando, a partir do sensível, a descoberta do que vem sendo obliterado pelas forças do esterilizante discurso do consumo massificado. De modo semelhante, a partir do Grande Bom Jardim, o Nóis de Teatro lança um projeto poético que busca rever a periferia pela via da arte de caminhar, do anúncio do artificial ${ }^{9}$ como potência poética, da flor de plástico como imagem inquietante ante a finitude sempre latente das flores naturais - no nosso caso em relação direta com o extermínio da juventude. Há um amor pelo bairro que, assim como o medo, age como uma ponta de faca cortante em nossa poética, inserindo-nos em paradoxos e conflitos não facilmente resolvíveis.

Reconhecemos que quando o medo se torna corpo, os passos se apressam, a respiração fica ofegante e a processualidade de uma descoberta é interrompida pela carga violenta de uma pseudolegítima defesa. Dessa maneira, aponta-se aqui a necessidade de compreender a ideia de caminhar pelas ruas não somente como um desafio poético que agencia a criação teatral, mas também como resistência política, como enfrentamento ao discurso de violência e medo impregnado na voz da comunicação em massa, performando outras práticas, outros desejos e não se entregando à ação por si só violenta desse universo de imagens que circulam em nosso imaginário corporal e virtual. Por isso mesmo, a necessidade de um mergulho que não se contenta com a primeira vista, com a primeira opinião, mas mexe na ferida com a ponta dessas facas afiadas, vazando o abcesso até chegar a seu ponto culminante. Vejamos a experiência da atriz Angélica Freire, a partir de uma das apresentações de $O$ jardim das flores de plástico:

Seguimos cortejo para uma rua ladeada pelo canal e casas a sua margem [...] Sempre me gerou medo aquela rua, principalmente pelos jovens sempre sentados à calçada logo no começo dela, estavam lá dia e noite. [...] Aquela ruazinha tão curta, tinha o costume de me amedrontar, mas naquela noite não. Eu intervi no meu medo e naquela rua curta, entrei e fui drasticamente mudada por ela, me senti imensamente satisfeita por estar ali e mais uma vez me vem a impressão de que vou lembrar

9. O plástico é um material usado nos três atos performáticos de $O$ jardim das flores de plástico. A partir da ideia de resíduo no mundo, ele tem nos provocado a pensar a reciclagem como agenciadora dos processos. Talvez, por isso, todos os figurinos e adereços usados no Ato 3 tenham sido feitos de plástico e outros materiais precários, conforme podemos ver nas fotos expostas. 
mesmo que dez anos passem para mim. (ASSOCIAÇÃO ARTíSTICA NÓIS DE TEATRO, 2015, p. 53)

Percebendo o que antes lhe era obliterado, a atriz avista, a partir do caminhar acionado pelo espetáculo, o que não lhe interessava antes. O que antes era visto como entulho humano, a lhe incomodar na esquina da rua, é revisto ao ater-se à efemeridade da experiência teatral vivida naquela noite: esta era a última chance de intervir no seu medo, tendo a cena teatral como a mola propulsora para um amor incógnito, percebido à última vista. Talvez, por isso, a atriz Doroteia Ferreira falava que o processo de montagem não a fazia apenas caminhar pelas ruas, mas flanar também sobre suas experiências, sobre suas memórias vivenciadas nos lugares por onde percorremos. Se é verdade - como fala Frei Betto - que a cabeça pensa a partir de onde os pés pisam, talvez seja exatamente por isso que durante os meses que passamos em laboratórios, a pulsão afetiva dos artistas envolvidos se fazia tão presente nos jogos e exercícios propostos. Esse processo de relação entre as memórias dos atores e dos espaços agenciou a criação de dez microcenas autobiográficas que, de tão pertinentes para o grupo, foram transformadas em vídeos publicados na internet ${ }^{10}$.

Esse tipo de inquietação tem sido revelador na poética do Nóis de Teatro, fazendo-nos pensar sobre quais contradições estão sendo alicerçadas nas cidades, questão de grande relevância para pensar a periferia, lançando-nos ao desenho de um projeto de teatro que busca rever, pela experiência da caminhada, as periferias de Fortaleza, vistas quase sempre pelo discurso globalizante como lugares de atraso e violência, mas que podem ser desconstruídas enquanto poética e política.

\section{Do carnaval à lentidão}

É interessado em rever a experiência do dia a dia, na vontade de repelir um cotidiano tão massacrante da comunidade onde vivemos, que nosso trabalho poético busca ocupar a rua da periferia com uma linguagem que

10. A série de vídeos Negros, como ficou chamada, pode ser visualizada no blog do Nóis de Teatro: <http://bit.ly/2u1NYuL>. 
seja convite para uma viagem, como convocou Waly Salomão. No caso de $O$ jardim das flores de plástico, que vinha se interessando pelo caminhar pelas ruas, foi muito importante adentrar os referenciais poéticos do carnaval e dos cortejos, observando e discutindo sobre os carnavais de rua de Fortaleza, as escolas de samba televisionadas, os blocos de axé e os trios elétricos, os "mela-mela" do interior do Ceará, além dos cortejos de maracatu e afoxé que desfilam na Av. Domingos Olímpio no Carnaval de Fortaleza. O que eles possuem em comum? Percebemos que o uso do espaço em deslocamento é um dos pontos de interseção entre essas diversas manifestações culturais de festa, o que nos deu margem para escolher como referencial para a cena o maracatu cearense. Contudo, foi compreendendo a singularidade dos processos de carnavalização ligados aos blocos de rua e às escolas de samba (ou no nosso caso de maracatu), que muito refletimos sobre a potência dessas dinâmicas na nossa encenação teatral. Partindo do ritual vivenciado no maracatu, nossa busca poética enquanto artistas de teatro de rua estava muito mais focada no acaso inumerável da cidade que na marcação ensaiada de uma escola na avenida ${ }^{11}$. Como aponta o arquiteto e professor da Universidade Federal de Minas Gerais, Roberto Andrés, em texto da revista Piseagrama:

No limite, chega-se à diferença entre bloco de rua e escola de samba. Enquanto esta opera na base do planejamento e do treino, com uma hierarquia bem definida, tendo o desfile como apogeu de algo construído por um grupo restrito, aquele não diferencia ensaio de performance, ver e ser visto se misturam, as muitas facetas do improviso aparecem e o acontecimento se torna não um espetáculo, mas um dispositivo caminhante de encontros. (ANDRÉS, 2015, grifo do autor)

Exatamente por isso é que as cenas, embora requeressem uma sequência elaborada de ensaios, buscavam muito mais vivenciar a errância enquanto jogo poético do que a virtuosidade de um desfile carnavalesco a ser contemplado. Essa percepção foi um dos pressupostos que guiou o processo criativo no sentido de pensar no corpo desses artistas que, para além da formalidade

11. "Se as escolas de samba são pontuadas por seus acertos, os blocos de rua poderiam dar mais valor ao erro. Em uma sociedade tão pautada pelo êxito, a errância traz algo que, no mínimo, oferece um contraponto a nossos automatismos mentais e abre outras vias de acesso para o que está ao redor" (ANDRÉS, 2015). 
de um ofício, jogam-se na rua para a festa. Em alguns momentos, passamos a nos tratar como artistas-foliões, brincantes de um espaço público que pode ser avivado a partir da nossa proposição poética. Uma lição que carregamos da nossa experiência de teatro de rua é a de que quando mobilizamos um afeto que se localiza em um território de espontaneidade, a recíproca do espectador quase sempre é a mesma, o que nos leva a buscar um estado de cena no qual o corpo possa de fato entregar-se ao lance afetivo do encontro com o outro e o que pode surgir desse movimento. $O$ ator Jonas de Jesus, refletindo sobre os carnavais que vivenciou, afirma que no tempo da brincadeira há

permissão para a empolgação, empolgação esta que contagia e se faz de convite para a empolgação do outro que agora torna-se mais um folião. A palavra folião traz, sem dúvidas, a imagem daquele(a) que quer se permitir outras sensações. (ASSOCIAÇÃO ARTÍSTICA NÓIS DE TEATRO, 2015, p. 49).

A quais outras sensações estamos dispostos, a não ser as que já conhecemos? A busca constante durante o processo foi essa vontade urgente de descontruir nossos afetos e nos permitir a sentir outras sensações, ver as ruas de outras formas. Desse modo, ao pensar em espontaneidade, talvez estejamos mais próximos de problematizar o organismo social, evidenciando um organismo sensorial, aberto à diferença e à transformação de si e do espaço em que atua. Por isso mesmo que $O$ jardim das flores de plástico traz fortes elementos da cultura afro-brasileira, reivindicando um corpo que, na busca por libertar-se das noções hegemônicas de cidade, assim como dos grilhões que a história do povo negro da periferia carrega, produz pontos de tensão sensíveis enquanto potência de jogo nesse caminhar sinuoso pela cidade. Assim, para além de um plano idealizado ou comumente demonizado, a energia dos Exus ${ }^{12}$ é saudada do começo ao fim do espetáculo, trazendo à tona a complexidade sonora, visual, discursiva e, porque não dizer, epistemológica de uma cena que tem por base um universo amplamente perseguido e marginalizado, tal qual os cidadãos dos subúrbios.

12. Exu é o Orixá que rege a comunicação e a liberdade no candomblé. Nas mitologias africanas, é ele quem abre os caminhos da rua, já que valoriza o movimento da vida. 
O que aqui se anuncia, mesmo que de forma breve, é a força mística que está inserida na encenação, que entende "o povo da rua" e o sagrado mítico ancestral como matéria poética e que muito tem a dizer sobre essa experiência de caminhada pelas periferias da cidade. Uma mística ancestral que sempre correu com a marginalidade periférica e negra, constantemente perseguida pela hegemonia de uma cultura branca e eurocêntrica. Desde o vermelho e o preto como cores predominantes na cena até o significado de um tambor que bate nas encruzilhadas, há muito mais mistérios nessa caminhada do que o numerado na escrita deste artigo. Ainda assim, é importante destacar que o negrume utilizado no espetáculo em hipótese alguma faz menção à "blackface" americana, prática teatral realizada por atores brancos que se pintavam de preto para representar, de forma estereotipada, a população negra. O rosto preto dos atores do nosso espetáculo remete aos referenciais de tradição do maracatu cearense e, ao utilizá-los, o trabalho demarca o viés ancestral e de empoderamento de um estado que é historicamente conhecido por não ter negros, como falado outrora. O que interessa pontuar é que nosso teatro opera buscando trazer para a comunidade outros referenciais para além dos já vivenciados de forma hegemônica nas ruas. Buscamos provocar o encontro com a diferença. Como aponta Jussara Trindade e Licko Turle (2008, p. 231),

a concepção artística de tempo e do espaço próprias do carnaval permite reunir elementos espaciais e temporais que normalmente encontram-se dispersos de forma inconciliável. Assim, o discurso carnavalesco se constitui numa forma de contestação social e política por excelência, ao fornecer imagens instantâneas, em linguagem direta e objetiva.

Munidos desses pressupostos, percebíamos uma dramaturgia-festa acontecendo naquelas ruas a partir do olhar curioso de algum espectador que abria o portão de uma casa e olhava, mesmo que envergonhado, o que poderia estar acontecendo, retirando-o momentaneamente do seu cotidiano. Foi entendendo o espetáculo como um dispositivo caminhante de encontros que compreendemos a ação política dessa dramaturgia-festa, percebendo que ela é capaz de agenciar, no elenco e no espectador, protagonismo urbano, desalienando o indivíduo e repelindo, mesmo que momentaneamente, o 
embrutecimento condicionado pelo peso do cotidiano de trabalho, pela falta de perspectivas e pelos meios de comunicação de massa.

Talvez seja possível afirmar que atuávamos, também, numa reação ao tempo acelerado, à pressa da voracidade do consumo em massa e ao fetiche idealizado pela imagem gentrificada e esterilizada das cidades contemporâneas. Ainda assim, é importante assumir que a periferia urbana não está ilesa da correria de um tempo produtivo, o que se colocou no processo como outro argumento instaurador da poética da caminhada. Resistindo à cidade veloz, panorâmica e onisciente, a dramaturgia da cena usava também como recurso a experiência do caminhar lento da comunidade, revelando outras lógicas, para além das vividas no cotidiano massivo da rapidez de um tempo lucrativo. Para chegar a essa dimensão em cena, as caminhadas realizadas pelo bairro, avivadas por um traço de distração, tiveram que obedecer a esse chamado, revelando-nos uma dimensão corpórea sobre o tempo que abre espaço para a experiência.

Como nos diz Milton Santos, "estamos descobrindo que, nas cidades, o tempo que comanda, ou vai comandar, é o tempo dos homens lentos" (2006, p. 220). Assim, processar um caminhar que se faz lento foi se revelando para nós como chave disparadora de outras experiências de cidade, sobretudo das periferias urbanas percorridas por corpos apressados entregues à urgência do trabalho para manter o pão de cada dia ou às imagens reinantes do medo. Por isso mesmo que a nossa dramaturgia-festa passa a ser pensada como um espaço de proposição de climas, variando da festa à densidade, do riso cômico ao reflexivo. Essa lentidão dos corpos em cortejo foi utilizada como recurso poético que alia a desaceleração do corpo que caminha à marcação dolente do maracatu tradicional cearense, caracterizado, em essência, por uma batida que rege o corpo por outras perspectivas rítmicas: lentidão e cadenciamento. O ritmo da cena, em muitos momentos, refazia-se a partir desse jogo com o tempo, com o cadenciamento de outro olhar, outro corpo, mais lento e mais suave, talvez por isso que o espetáculo levasse mais de uma hora e meia caminhando pelas ruas. Interessante perceber o que o maracatu cearense evidencia essa experiência estética caminhante. Parece que o tempo cadenciado da manifestação afro-brasileira nos indica também outro modo de habitar a cidade, talvez marca resistente de um corpo negro 
escravizado ao trabalho acelerado e lucrativo que, no espaço de folguedo, reage de forma sensível a fabulação de outra lógica.

A partir dessa experiência, talvez possamos dizer que seja mais valioso pensar a cidade a partir da noção de lentidão desses corpos negros e marginais que caminham pela urbe, colocando o corpo criador, seja do artista ou do espectador, num jogo de afetação e atravessamento para, a partir de um contexto e uma conjuntura, lançar-se de fato a uma produção poética inventiva. Exatamente por isso é que cada vez mais me parece que a potência do plural está na especificidade do singular, que a política do mundo está nas micropolíticas do cotidiano, e que a potência de ação da arte está nas conjunturas e contextos de suas processualidades e não na obra fixa manufaturada de um produto exclusivamente direcionado à venda.

\section{Referências bibliográficas}

ANDRÉS, R. O cortejo errante: o carnaval como via de acesso a lugares esquecidos da cidade, retomada do protagonismo pedestre e dispositivo caminhante de encontros. Piseagrama, Belo Horizonte, n. 7, p. 79-87, 2015.

ANJOS, M. Local/global: arte em trânsito. Rio de Janeiro: Jorge Zahar, 2005.

ASSOCIAÇÃO ARTÍSTICA NÓIS DE TEATRO. 0 jardim das flores de plástico. Ato 3: por baixo do saco preto. Relatório de atividades. Fortaleza, 2015. Disponível em: <https://goo.gl/WgB2BQ>. Acesso em: 31 jan. 2017.

BHABA, H. K. Introducción narrar la nación. In: (comp.). Nación y narración. Buenos Aires: Siglo Veintiuno, 2010.

BRASIL. Secretaria-Geral da Presidência da República. Secretaria Nacional de Juventude. Índice de vulnerabilidade juvenil à violência e desigualdade racial 2014. Brasília, DF: Secretaria-Geral da Presidência da República; Secretaria Nacional de Juventude, 2015.

JACQUES, P. B. Elogio aos errantes. Salvador: Edufba, 2012.

LEPECKI, A. Coreopolítica e coreopolícia. Ilha, Florianópolis, v. 13, n. 1, p. 41-60, 2012.

OITICICA, H. Museu é o mundo. Rio de Janeiro: Azougue, 2011.

SALOMÃO, W. Poesia total. São Paulo: Companhia das Letras, 2014.

SANTOS, M. A natureza do espaço: técnica e tempo, razão e emoção. São Paulo: Edusp, 2006. 
O Jardim das flores de plástico: caminhos poéticos de um teatro negro e periférico

TRINDADE, J.; TURLE, L. (orgs.). Tá na rua: teatro sem arquitetura, dramaturgia sem literatura, ator sem papel. Rio de Janeiro: Instituto Tá Na Rua para as Artes, Educação e Cidadania, 2008.

VENTURA, Z. Cidade partida. São Paulo: Companhia das Letras, 1994.

Recebido em 23/04/2017

Aprovado em 10/06/2017

Publicado em 05/09/2017 